\title{
Radiological Diagnosis
}

\section{We ask: What is the diagnosis?}

Female, aged 4 years and 6 months. Normal birth

Progressive hoarseness from 8 months of age

Four ICU admissions for respiratory insufficiency, submitted to tracheostomy at the age of 1 year and 8 months

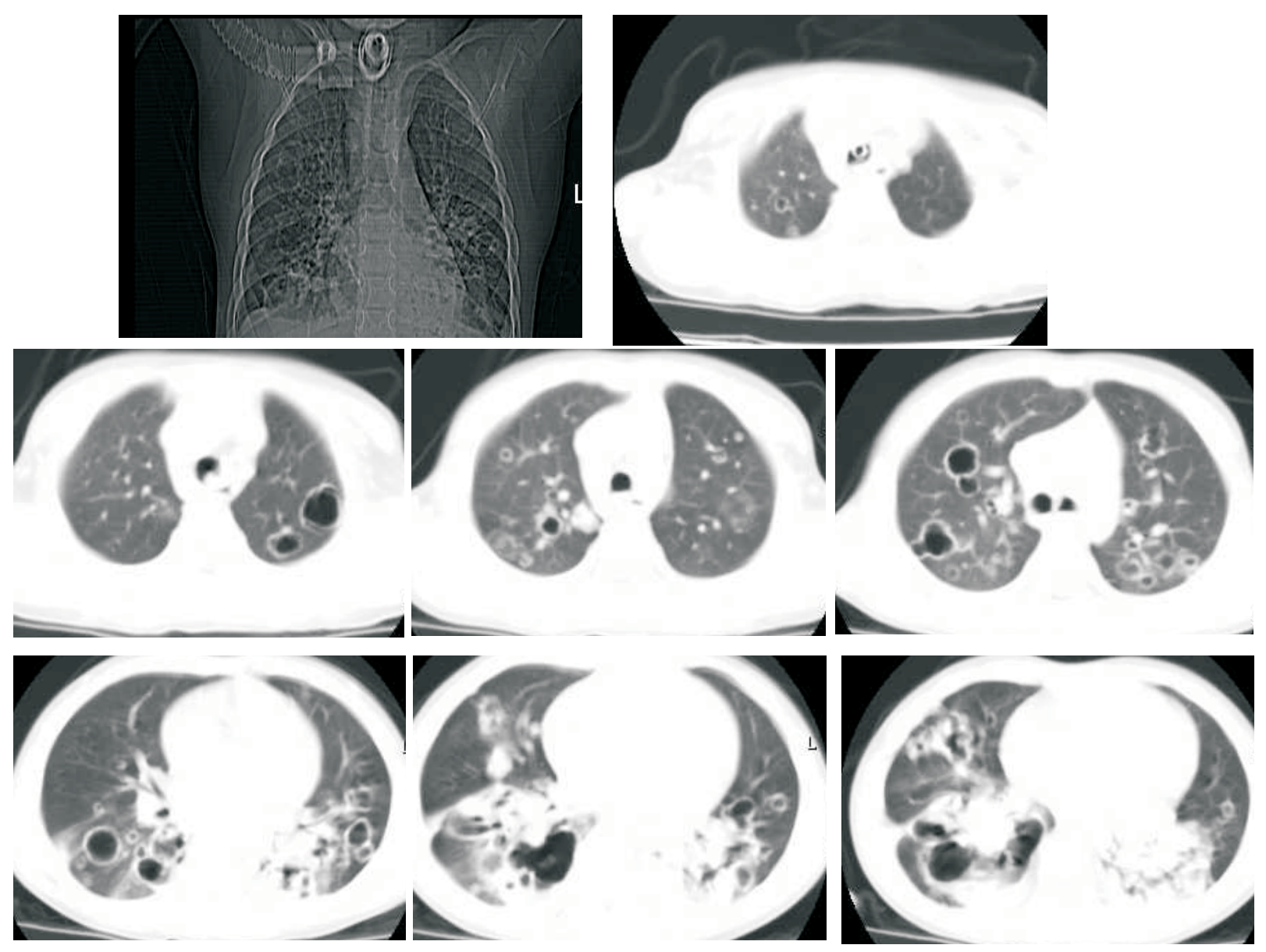

MARCOS IKAWA, GUSTAVO S. P. MEIRELLES, DANY JASINOWODOLINSKI, NESTOR MÜLLER Departamento de Diagnóstico por lmagem da UNIFESP,

Department of Radiology, Vancouver General Hospital, University of British Columbia

This section is intended to encourage a diagnostic approach based on clinical and radiographic findings. We invite all of our readers to participate.

Submit your diagnosis by completing the form you will find on our website (www.jornaldepneumologia.com.br) or by sending an e-mail to jpneumo@terra.com.br. Remember to include the full name of your institution. The images shown here are those that were most relevant in making the final diagnosis. In the next issue of the journal, we will publish the diagnosis for this case, along with the names of those who submitted correct responses. 